ORIGINAL ARTICLE

\title{
The prevalence of melanocytic naevi among schoolchildren in South Hungary
}

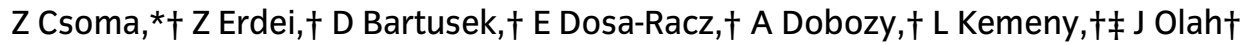 \\ † Department of Dermatology and Allergology, University of Szeged, Szeged, Hungary, \\ ‡ Dermatological Research Group of the Hungarian Academy of Sciences and the University of Szeged, Szeged, Hungary
}

\begin{abstract}
Keywords
health educational programme, malignant melanoma, melanocytic naevi, pigmentary trait, sun exposure

*Corresponding author, Department of Dermatology and Allergology, University of Szeged, PO Box 427, H-6701 Szeged, Hungary, tel. +36 625 45277; fax +36 625 45954;

E-mail:csomazs@mail.derma.szote.u-szeged.hu

Received: 25 October 2007,

accepted 7 May 2008

DOI: $10.1111 / j .1468-3083.2008 .02887 . x$
\end{abstract}

\begin{abstract}
Background Malignant melanoma is an increasing public health problem worldwide; accordingly, identification of the constitutional and environmental factors which contribute to the development of the disease, and hence identification of the individuals at high risk of melanoma, is an indispensable step in all primary prevention efforts.

Objectives This paper aims to assess the prevalence of different pigmented lesions among schoolchildren and to investigate their relationship with phenotypic pigmentary characteristics, sun exposure and other factors.

Patients/methods A cross-sectional study was performed in two secondary schools in Szeged, Hungary. A total of 1320 schoolchildren, aged 14 to 18 years, underwent a whole-body skin examination. A standardized questionnaire was used to collect data on phenotypic, sun exposure and other variables.

Results One to 10 common melanocytic naevi were found in $27 \%$ of the participants, and the naevus numbers were in the range of $10-100$ in $67 \%$; $5.4 \%$ of them had more than 100 common melanocytic naevi. The prevalence of clinically atypical naevi was $24.3 \%$. Statistically significant associations were found between the number of pigmented lesions and gender, hair colour, eye colour, skin phototype, a history of severe painful sunburns and a family history of a large number of melanocytic naevi.

Conclusion Our study population displayed a markedly high prevalence of clinically atypical melanocytic naevi. Moreover, a considerable proportion of the investigated individuals had multiple common melanocytic naevi. Since the presence of a large number of melanocytic naevi is a strong predictor for future melanoma development, health educational programmes on melanoma prevention should be aimed at young age groups.
\end{abstract}

\section{Introduction}

During the past few decades, the incidence of cutaneous malignant melanoma (MM) has been increasing rapidly worldwide, particularly among Caucasian populations. ${ }^{1-7}$ A similar tendency has been observed in Hungary in the past 50 years; the mortality rate from MM has approximately doubled since 1975. The National Cancer Registry data reveal that MM is currently the 15 th most frequently diagnosed malignancy in Hungary. In 2000, the average incidence was 12 per 100000 inhabitants, but by 2005 , it had increased to 18 per 100000 , similarly to the overall European change. ${ }^{8-11}$ A significantly higher incidence is observed in the southernmost part of the country, in the Szeged area. In comparison with the 17 new cases diagnosed at our Department in 2000, in 2006, we diagnosed 30 new cases per 100000.

A number of epidemiological studies performed in an attempt to identify risk factors for the development of MM have demonstrated the roles of both constitutional and environmental factors. Exposure to ultraviolet (UV) irradiation is the major environmental cause of MM. It is 
clear that a history of severe sunburn, particularly in early childhood, and intermittent acute intense sun exposures markedly increase the relative risk of MM. ${ }^{1,2,5,6,12-21}$ Individuals with specific phenotypic characteristics, such as skin phototype I or II, blond or red hair, a light eye colour or a tendency to freckle, are at higher risk of the development of melanoma. ${ }^{3,4,13-15,19,20,22,23}$ Other well-established risk factors include a family history of MM, a personal history of MM or non-melanoma skin cancers, immunosuppression and xeroderma pigmentosum. Other potential risk factors are an elevated socioeconomic status, increasing age, regular UV exposure on sun beds, and prior therapy with psoralen and UVA light. ${ }^{1,2,5,14}$

Epidemiologic data indicate that the presence of a large number of common melanocytic naevi (CMN) and clinically atypical melanocytic naevi (CAMN) represents the most important independent phenotypic risk factor for the development of $\mathrm{MM}$ in fair-skinned populations. ${ }^{3,4,13-16,22-29}$

Most pigmented naevi of the skin are acquired; fewer than $2 \%$ of white newborns have congenital melanocytic naevi $(\mathrm{CN})$. CMN appear in early childhood. The number of pigmented lesions increases continuously throughout childhood, and the maximum density is attained during puberty and early adulthood. It is well documented that pigmentary traits and genetic, hormonal and environmental factors which play important roles in melanoma development also considerably influence the naevus count of an individual. . $6,30-39^{-3}$

In the course of the present study, we aimed to assess the prevalence of different pigmented lesions among Hungarian schoolchildren aged 14 to 18 years. We additionally investigated the relationships between the number of pigmented lesions and phenotypic pigmentary characteristics, sun exposure and other factors. As far as we are aware, this is the first survey from this region of Europe on the prevalence of melanocytic naevi and associated factors in a large sample of adolescents and young adults.

\section{Methods}

\section{Subjects}

One thousand three hundred and twenty schoolchildren of Caucasian origin, aged 14 to 18 years (614 boys, mean age: 16.28 years and 706 girls, mean age: 16.25 years), were selected for this study. Of these, 905 (68.6\%; 384 boys, mean age: 16.09 years and 521 girls, mean age: 16.04 years) participated in the inquiry. The survey was conducted in two secondary schools in the city of Szeged, between September 2002 and May 2003. Szeged is situated in the south-east of Hungary, at latitude $46^{\circ} 15^{\prime}$ north, longitude $20^{\circ} 15^{\prime}$ east.
After approval and permission had been obtained from the Institutional Review Board of Albert Szent-Györgyi Medical Centre at the University of Szeged, the crucial points and aims of the present survey were explained to the school principals and teachers. The study was also discussed with the schoolchildren, who were told that participation was voluntary.

The study was based on three major elements: a health education programme, a clinical skin examination and a standardized questionnaire.

\section{Skin examination}

All subjects underwent a whole-body examination, excluding the scalp and the anogenital area. The freckles, CMN, CAMN, CN and lentigines were identified according to their clinical features. Melanocytic naevi were determined on the basis of the standardized international protocol according to English et al..$^{40}$ The numbers of CMN, CAMN and lentigines were classified in four categories: none, $<10,10-100$, or $>100$, and the presence or absence of CN and freckles was also recorded in each subject.

Skin examinations were performed by two experienced dermatologists and two senior medical students. Prior to the start of the survey, the two senior medical students had been trained in the clinical classification of the different pigmented lesions. The validity of the naevus counting procedure of the investigators was assessed by examining several volunteers $(n=30)$ before the study. The interobserver reliability was assessed by means of the Friedman ANova test, and the agreement was found to be excellent $(P=0.922)$. If the diagnosis of CAMN arose, subjects were always examined by a well-trained, experienced dermato-oncologist (J.O.) in order to confirm the diagnosis.

Pigmentary traits such as eye colour and hair colour were evaluated in each subject. Eye colour was assessed on a three-category scale $(1=$ dark-brown, 2 = lightbrown or hazel, 3 = blue, green or grey). Hair colour was classified into four categories $(1=$ black, $2=$ brown, $3=$ blond, $4=$ red).

\section{Interview}

After the clinical examination, a standardized questionnaire was distributed to all the schoolchildren for completion in consultation with their parents.

Skin phototype was assessed on the Fitzpatrick scale, which is based on a person's reaction to 30 min of midday sunlight for the first time in the summer ( $\mathrm{I}=$ always burns, never tans; II = always burns, sometimes tans; III = sometimes burns, always tans; IV = never burns, always tans). 
Data were recorded with regard to the use of sunlamps and sun beds (never, occasionally, or regularly), the use of sunscreens during sunbathing or various summer holiday activities and a history of severe sunburn during childhood. The sunburn history was based on the following question: 'Have you ever been sunburnt so severely that you had blistering or painful erythema?' The answers were grouped as never, 1-5 times, or $>5$ times. The questionnaire sought information about the number of hours usually spent outdoors daily during summer (1-2 h, 2-4 h or $>4 \mathrm{~h}$ ).

The subjects were asked if they had heard about the harmful effects of sunlight, if they regularly checked the pigmented lesions of their skin and whether they suffered from any disease, or took any medicine regularly.

Answers to questions dealing with the family history of $\mathrm{MM}$ and the possible presence of large numbers of melanocytic naevi among parents and siblings were also recorded.

\section{Health educational programme}

One of the essential goals of our present study was to initiate a health educational programme among schoolchildren with the aim of extending their knowledge relating to the primary and secondary prevention of MM. As sunlight exposure is the most important environmental factor in the pathogenesis of MM, we provided them with information on the potential harmful effects of UV irradiation, and on the various methods of sun protection. The recommended sun protection behaviour includes regular application of broad-spectrum sunscreens with a sun protection factor (SPF) of at least 15, the avoidance of sunburn, wearing protective clothing and general reduction of UV radiation exposure. ${ }^{1,4,5}$ Other important risk factors were mentioned in detail, and we focused on the roles of different pigmented lesions in the development of MM. The schoolchildren were educated in the regular self-examination of melanocytic naevi of the skin by means of the ABCDE guidelines, which promote the diagnosis of early melanomas. Their attention was called to the importance of consulting a dermatologist without delay in the event of any significant change in a preexisting pigmented lesion, or the appearance of a new pigmented lesion. Educational materials on skin self-examination and the ABCDE guidelines were provided to the participants. After the clinical examinations, subjects with large numbers of CMN and CAMN were referred to our Department for examinations of the suspected lesions by digital dermoscopy. Total cutaneous photographs were taken, and regular skin examinations were suggested every 6-12 months for these high-risk individuals.

\section{Statistical analyses}

The correlations between the prevalence of pigmented lesions, and phenotypic, sun exposure and other variables were assessed by using the Pearson chi-squared test, and the chi-squared test for a linear trend. Odds ratios (OR) and their 95\% confidence intervals (95\% CI) were calculated and interpreted to estimate the relative risk of the development of pigmented lesions. All $P$-values calculated were two sided, and a significance level of 0.05 was assumed. Statistical analyses were performed with SPSS version 15.0 software.

\section{Results}

\section{The prevalence of freckles in relation to gender, phenotypic pigmentary characteristics and sun exposure variables}

Almost 20\% of the schoolchildren had freckles (data not shown). The girls were more likely than the boys to have freckles; $48.6 \%$ of the participants had dark-brown eyes, $12.5 \%$ had light-brown or hazel eyes, and $38.9 \%$ had blue, green or grey eyes. The light eye-coloured individuals exhibited a higher prevalence rate of freckles relative to those with dark eyes; $77.9 \%$ of the subjects had brown hair, $16.5 \%$ had blond hair, and $4.9 \%$ had black hair; there were only a very small number of subjects with red hair $(n=7)$. The hair colour proved not to have any significant association with the density of freckles. The individuals whose skin tended to burn on the first exposure to strong sunlight in the summer (skin phototypes I and II) had a substantially higher density of freckles as compared with those who burned infrequently and tanned easily (skin phototypes III and IV). Severe painful sunburn was reported in $13.4 \%$ of the schoolchildren. A significantly greater proportion of those who had ever experienced painful sunburn had freckles. The majority of the schoolchildren $(83.17 \%)$ applied sunscreens on sunny summer days. $0.7 \%$ of them stated that they used sun beds regularly, while $13.4 \%$ did so occasionally. We did not observe a significant correlation between the use of sunscreens or sun beds and the prevalence of freckles (Table 1).

\section{The prevalence of $\mathrm{CN}$ in relation to gender and phenotypic pigmentary characteristics}

$\mathrm{CN}$ were detected in $6.21 \%$ of the schoolchildren (data not shown); $8.6 \%$ of the boys, as compared with $5.8 \%$ of the girls, had CN. The prevalence of CN was $8.18 \%$ among those with dark-brown eyes, $7.08 \%$ among those with hazel or light-brown eyes, and 5.4\% among those with light eyes. The rate of occurrence of $\mathrm{CN}$ was $7.66 \%$ among 
Table 1 The relationships between gender, constitutional and sun exposure variables and the prevalence of freckles in Hungarian schoolchildren aged $14-18$ years (905 subjects with complete data)

\begin{tabular}{|c|c|c|}
\hline & Freckles & \\
\hline & Present & Absent \\
\hline \multicolumn{3}{|l|}{ Gender } \\
\hline Male & 61 & 323 \\
\hline Female & 110 & 411 \\
\hline$P$-value & $0.0471^{\star}$ & \\
\hline$O R$ & $1.417(1.004 ; 2.001)$ & \\
\hline \multicolumn{3}{|l|}{ Hair colour $(n=898)$} \\
\hline Black & 10 & 34 \\
\hline Brown & 119 & 586 \\
\hline Blond & 35 & 114 \\
\hline$P$-value & $0.262^{\star \star}$ & \\
\hline \multicolumn{3}{|l|}{ Eye colour } \\
\hline Brown & 73 & 367 \\
\hline Light brown/hazel & 21 & 92 \\
\hline Blue/green/grey & 77 & 275 \\
\hline$P$-value & $0.06^{\star *}$ & \\
\hline \multicolumn{3}{|l|}{ Skin phototype } \\
\hline$|-| \mid$ & 131 & 423 \\
\hline III-IV & 40 & 311 \\
\hline$P$-value & $0.0001^{\star}$ & \\
\hline$O R$ & $2.408(1.641 ; 3.532)$ & \\
\hline \multicolumn{3}{|c|}{ History of severe painful sunburns } \\
\hline None & 131 & 653 \\
\hline Yes & 40 & 81 \\
\hline$P$-value & $0.00002^{\star}$ & \\
\hline$O R$ & $2.462(1.613 ; 3.757)$ & \\
\hline \multicolumn{3}{|l|}{ Use of sunbeds } \\
\hline Never & 148 & 630 \\
\hline Yes & 23 & 104 \\
\hline$P$-value & $0.8063^{\star}$ & \\
\hline \multicolumn{3}{|c|}{ Time spent outdoors in summer (h) } \\
\hline $1-2$ & 12 & 52 \\
\hline $2-4$ & 69 & 274 \\
\hline$>4$ & 90 & 408 \\
\hline$P$-value & $0.587^{\star \star}$ & \\
\hline
\end{tabular}

*: Pearson chi-squared.

$* *$ : chi-squared for linear trend.

the children with brown hair; the rates were very similar among individuals with blond or with black hair $(4.55 \%$ and $4.7 \%$, respectively). The prevalence of $\mathrm{CN}$ was not related to gender, hair colour, eye colour or skin type (Table 2 ).

\section{The prevalence of $\mathrm{CMN}$ in relation to gender, phenotypic pigmentary characteristics and sun exposure variables}

The vast majority of the subjects had CMN (fig. la). There was a significantly higher prevalence of CMN among the boys. A lighter eye colour was accompanied by an
Table 2 The relationships between gender and constitutional variables and the prevalence of $\mathrm{CN}$ in Hungarian schoolchildren aged 14-18 years (905 subjects with complete data)

\begin{tabular}{lcc}
\hline & \multicolumn{2}{c}{ Congenital naevi } \\
\cline { 2 - 3 } & Present & Absent \\
\hline Gender & & \\
Male & 33 & 351 \\
Female & 30 & 491 \\
$P$-value & $0.0976^{\star}$ & \\
Hair colour $(n=898)$ & & \\
Black & 2 & 42 \\
Brown & 54 & 651 \\
Blond & 7 & 142 \\
$P$-value & $0.491^{\star \star}$ & \\
Eye colour & & 404 \\
Brown & 36 & 105 \\
Light brown/hazel & 8 & 333 \\
Blue/green/grey & 19 & \\
$P$-value & $0.127^{\star \star}$ & 517 \\
Skin phototype & & 325 \\
I-II & 37 & \\
III-IV & 26 & \\
$P$-value & $0.674^{\star}$ & \\
\hline
\end{tabular}

*: Pearson chi-squared.

$\star *$ : chi-squared for linear trend.

increased rate of CMN occurrence, but the hair colour did not display a significant association with the density of CMN. Those with skin phototypes I or II had substantially higher densities of CMN than those with skin phototypes III or IV. There was no significant correlation between a history of sunburn, the use of sunscreens or sun beds, and the prevalence of CMN. More than half of the participants reported that they spent more than $4 \mathrm{~h}$ outdoors daily during the summer. Those who spent more time outdoors did not have more CMN than those who usually spent fewer hours outdoors (Table 3).

\section{The prevalence of lentigines in relation to gender, phenotypic pigmentary characteristics and sun exposure variables}

Lentigines were likewise seen in most of the cases (fig. 1c). The number of lentigines was strongly associated with the number of CMN (chi-squared for linear trend, $P=0.0001$; data not shown). Lenitigines were significantly more prevalent among the boys. The prevalence of lentigines was not related to the eye colour, but there was a significant tendency towards an increasing number of lentigines with lightening hair colour. The schoolchildren with skin phototypes I or II had substantially higher densities of lentigines than did those with skin 
(a) The prevalence of common melanocytic naevi

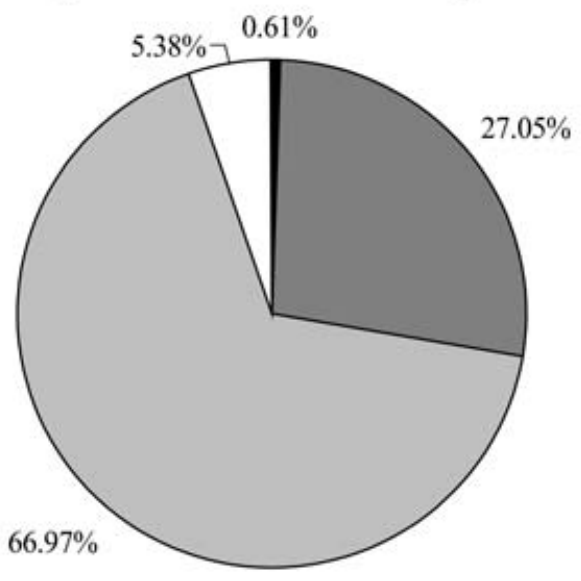

(b) The prevalence of clinically atypical naevi

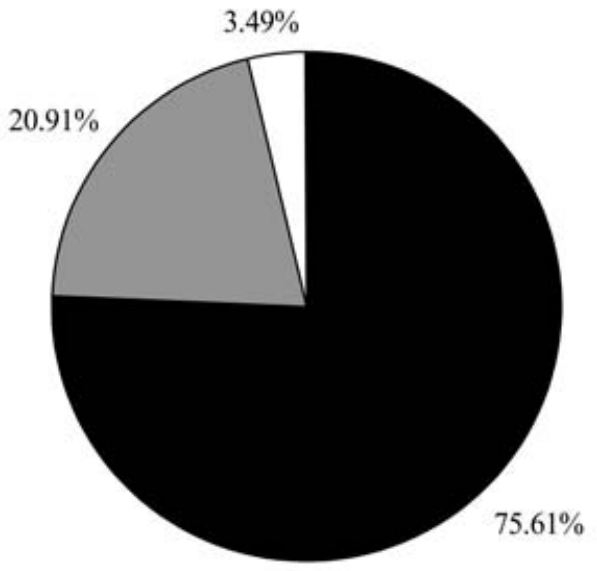

(c) The prevalence of lentigines

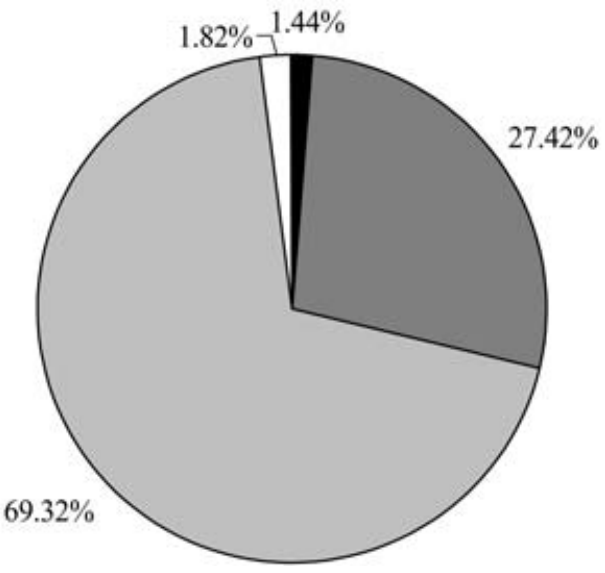

fig. 1 The prevalence of pigmented skin lesions among 14-to 18-year-old schoolchildren $(n=1320)$.
Table 3 The relationships between gender, constitutional and sun exposure variables and the prevalence of $\mathrm{CMN}$ in Hungarian schoolchildren aged $14-18$ years (905 subjects with complete data)

\begin{tabular}{|c|c|c|c|c|}
\hline & \multicolumn{4}{|c|}{$\begin{array}{l}\text { Number of common } \\
\text { melanocytic naevi }\end{array}$} \\
\hline & $N=0$ & $<10$ & $10-100$ & $>100$ \\
\hline \multicolumn{5}{|l|}{ Gender } \\
\hline Male & 2 & 77 & 279 & 26 \\
\hline Female & 3 & 171 & 328 & 19 \\
\hline$P$-value & \multicolumn{4}{|c|}{$0.00001^{\star \star}$} \\
\hline \multicolumn{5}{|l|}{ Hair colour $(n=898)$} \\
\hline Black & 0 & 13 & 28 & 3 \\
\hline Brown & 4 & 199 & 470 & 32 \\
\hline Blond & 1 & 31 & 107 & 10 \\
\hline$P$-value & \multicolumn{4}{|l|}{$0.118^{\star \star}$} \\
\hline \multicolumn{5}{|l|}{ Eye colour } \\
\hline Brown & 5 & 128 & 288 & 19 \\
\hline Light brown/hazel & 0 & 29 & 81 & 3 \\
\hline Blue/green/grey & 0 & 91 & 238 & 23 \\
\hline$P$-value & \multicolumn{4}{|c|}{$0.045^{\star \star}$} \\
\hline \multicolumn{5}{|l|}{ Skin phototype } \\
\hline $1-11$ & 0 & 134 & 387 & 33 \\
\hline III-IV & 5 & 114 & 220 & 12 \\
\hline$P$-value & \multicolumn{4}{|c|}{$0.0002^{\star \star}$} \\
\hline \multicolumn{5}{|c|}{ History of severe painful sunburns } \\
\hline None & 5 & 216 & 523 & 40 \\
\hline Yes & 0 & 32 & 84 & 5 \\
\hline$P$-value & \multicolumn{4}{|l|}{$0.789 * *$} \\
\hline \multicolumn{5}{|l|}{ Use of sunbeds } \\
\hline Never & 3 & 219 & 515 & 41 \\
\hline Yes & 2 & 29 & 92 & 4 \\
\hline$P$-value & \multicolumn{4}{|c|}{$0.874^{\star *}$} \\
\hline \multicolumn{5}{|c|}{ Time spent outdoors in summer (h) } \\
\hline $1-2$ & 0 & 21 & 40 & 3 \\
\hline $2-4$ & 1 & 82 & 244 & 16 \\
\hline$>4$ & 4 & 145 & 323 & 26 \\
\hline$P$-value & \multicolumn{4}{|l|}{$0.499 * *$} \\
\hline
\end{tabular}

*: Pearson chi-squared.

**: chi-squared for linear trend.

phototypes III or IV. A significantly greater proportion of those who had ever experienced painful sunburn had lentigines. There was no significant correlation between the use of sunscreens or sun beds, and the prevalence of lentigines (Table 4).

The prevalence of CAMN in relation to gender, phenotypic pigmentary characteristics and sun exposure variables

The prevalence of CAMN was $24.39 \% ; 3.49 \%$ of the schoolchildren had > 10 CAMN; there was only 1 with $>100$ CAMN (fig. lb). A statistically significant correlation was found between the number of CAMN and the 
Table 4 The relationships between gender, constitutional and sun exposure variables and the prevalence of CAMN in Hungarian schoolchildren aged $14-18$ years (905 subjects with complete data)

\begin{tabular}{|c|c|c|c|c|}
\hline & \multicolumn{4}{|c|}{ Number of lentigines } \\
\hline & $N=0$ & $<10$ & $10-100$ & $>100$ \\
\hline \multicolumn{5}{|l|}{ Gender } \\
\hline Male & 3 & 79 & 288 & 14 \\
\hline Female & 10 & 160 & 345 & 6 \\
\hline$P$-value & \multicolumn{4}{|c|}{$0.00002^{\star \star}$} \\
\hline \multicolumn{5}{|l|}{ Hair colour ( $n=898)$} \\
\hline Black & 2 & 11 & 30 & 1 \\
\hline Brown & 11 & 190 & 493 & 11 \\
\hline Blond & 0 & 34 & 109 & 6 \\
\hline$P$-value & \multicolumn{4}{|c|}{$0.038^{* *}$} \\
\hline \multicolumn{5}{|l|}{ Eye colour } \\
\hline Brown & 6 & 119 & 308 & 7 \\
\hline Light brown/hazel & 2 & 25 & 83 & 3 \\
\hline Blue/green/grey & 5 & 95 & 242 & 10 \\
\hline$P$-value & \multicolumn{4}{|c|}{$0.722^{\star \star}$} \\
\hline \multicolumn{5}{|l|}{ Skin phototype } \\
\hline I-II & 4 & 129 & 406 & 15 \\
\hline III-IV & 9 & 110 & 227 & 5 \\
\hline$P$-value & \multicolumn{4}{|c|}{$0.0002^{\star \star}$} \\
\hline \multicolumn{5}{|c|}{ History of severe painful sunburns } \\
\hline None & 12 & 215 & 544 & 13 \\
\hline Yes & 1 & 24 & 89 & 7 \\
\hline$P$-value & \multicolumn{4}{|c|}{$0.01 \star \star$} \\
\hline \multicolumn{5}{|l|}{ Use of sunbeds } \\
\hline Never & 11 & 211 & 536 & 20 \\
\hline Yes & 2 & 28 & 97 & 0 \\
\hline$P$-value & \multicolumn{4}{|c|}{$0.66^{\star *}$} \\
\hline \multicolumn{5}{|c|}{ Time spent outdoors in summer (h) } \\
\hline $1-2$ & 0 & 21 & 42 & 1 \\
\hline $2-4$ & 5 & 86 & 244 & 8 \\
\hline$>4$ & 8 & 132 & 347 & 11 \\
\hline$P$-value & \multicolumn{4}{|c|}{$0.96^{\star *}$} \\
\hline
\end{tabular}

*: Pearson chi-squared.

**: chi-squared for linear trend.

prevalence of CMN (chi-squared for linear trend, $P=$ 0.0001 ). Only $7.3 \%$ of the subjects with $<10 \mathrm{CMN}$ had CAMN, whereas about 30\% of those with 10-100 CMN had at least one CAMN. We found CAMN in 54.9\% of those who had a large number of CMN (> 100 naevi). The subjects with $>100 \mathrm{CMN}$ had significantly more CAMN than those with < $100 \mathrm{CMN}$ (data not shown).

A significantly higher prevalence of CAMN was observed among the boys. A lighter eye colour was associated with an increased rate of CAMN occurrence. The hair colour was not significantly related to the density of CAMN. Skin phototypes I and II were associated with a substantially higher rate of occurrence of CAMN. We did not observe a significant association between a history of sunburn, the use of sunscreens or sun beds, and the prevalence of
Table 5 The relationships between gender, constitutional and sun exposure variables and the prevalence of lentigines in Hungarian schoolchildren aged $14-18$ years ( 905 subjects with complete data)

\begin{tabular}{|c|c|c|c|}
\hline & \multicolumn{3}{|c|}{$\begin{array}{l}\text { Number of clinically } \\
\text { atypically naevi }\end{array}$} \\
\hline & $N=0$ & $<10$ & $>10$ \\
\hline \multicolumn{4}{|l|}{ Gender } \\
\hline Male & 274 & 92 & 18 \\
\hline Female & 414 & 97 & 10 \\
\hline$P$-value & $0.002^{\star \star}$ & & \\
\hline \multicolumn{4}{|l|}{ Hair colour ( $n=898$ ) } \\
\hline Black & 32 & 12 & 0 \\
\hline Brown & 547 & 136 & 22 \\
\hline Blond & 103 & 40 & 6 \\
\hline$P$-value & $0.1 * *$ & & \\
\hline \multicolumn{4}{|l|}{ Eye colour } \\
\hline Brown & 352 & 79 & 9 \\
\hline Light brown/hazel & 81 & 29 & 3 \\
\hline Blue/green/grey & 255 & 81 & 16 \\
\hline$P$-value & $0.005^{\star \star}$ & & \\
\hline \multicolumn{4}{|l|}{ Skin phototype } \\
\hline I-II & 396 & 139 & 19 \\
\hline III-IV & 292 & 50 & 9 \\
\hline$P$-value & $0.0003^{\star x}$ & & \\
\hline \multicolumn{4}{|c|}{ History of severe painful sunburns } \\
\hline None & 594 & 166 & 24 \\
\hline Yes & 94 & 23 & 4 \\
\hline$P$-value & $0.736^{\star *}$ & & \\
\hline \multicolumn{4}{|l|}{ Use of sunbeds } \\
\hline Never & 589 & 163 & 26 \\
\hline Yes & 99 & 26 & 2 \\
\hline$P$-value & $0.411^{\star *}$ & & \\
\hline \multicolumn{4}{|c|}{ Time spent outdoors in summer (h) } \\
\hline $1-2$ & 42 & 20 & 2 \\
\hline $2-4$ & 261 & 68 & 14 \\
\hline$>4$ & 385 & 101 & 12 \\
\hline$P$-value & $0.085^{\star \star}$ & & \\
\hline
\end{tabular}

*: Pearson chi-squared.

$\star *$ : chi-squared for linear trend.

$\mathrm{Cl}=95 \%$ confidence interval.

CAMN. A higher proportion of those who spent only 1-2 h outside daily during the summer holidays had CAMN in comparison with those who spent more than $4 \mathrm{~h}$ outside (the level of statistical significance was not reached; Table 5).

\section{The prevalence of $C M N$ and CAMN in relation to a family history of $M M$ and a large number of melanocytic naevi}

A positive family history of MM was reported by 11 of the schoolchildren. A positive family history of MM was not associated with a higher prevalence of CMN or CAMN (Table 6). 
Table 6 The relationships between a family history of MM and the prevalence of CMN and CAMN in Hungarian schoolchildren aged 14-18 years (905 subjects with complete data)

\begin{tabular}{|c|c|c|c|c|c|c|c|}
\hline & \multicolumn{4}{|c|}{ Number of common melanocytic naevi } & \multicolumn{3}{|c|}{ Number of clinically atypical naevi } \\
\hline & $N=0$ & $<10$ & $10-100$ & $>100$ & $N=0$ & $<10$ & $>10$ \\
\hline \multicolumn{8}{|c|}{ Family history of malignant melanoma } \\
\hline Yes & 0 & 1 & 10 & 0 & 7 & 4 & 0 \\
\hline No & 4 & 249 & 602 & 39 & 676 & 188 & 30 \\
\hline$P$-value & $0.34^{\star *}$ & & & & $0.583^{* *}$ & & \\
\hline
\end{tabular}

$\star *$ : chi-squared for linear trend.

Table 7 The relationships between a family history of a large number of melanocytic naevi and the prevalence of CMN and CAMN in Hungarian schoolchildren aged $14-18$ years (905 subjects with complete data)

\begin{tabular}{|c|c|c|c|c|c|c|c|}
\hline & \multicolumn{4}{|c|}{$\begin{array}{l}\text { Number of common } \\
\text { melanocytic naevi }\end{array}$} & \multicolumn{3}{|c|}{$\begin{array}{l}\text { Number of clinically } \\
\text { atypical naevi }\end{array}$} \\
\hline & $N=0$ & $<0$ & $10-100$ & $>100$ & $N=0$ & $<10$ & $>10$ \\
\hline \multicolumn{8}{|c|}{ Large number of melanocytic naevi in both parents and sibling } \\
\hline Yes & 0 & 20 & 98 & 12 & 72 & 49 & 9 \\
\hline No & 2 & 229 & 515 & 29 & 607 & 145 & 23 \\
\hline$P$-value & $0.0002^{\star}$ & & & & 0.0001 & & \\
\hline \multicolumn{8}{|c|}{ Large number of melanocytic naevi in parents or siblings } \\
\hline Yes & 0 & 46 & 195 & 23 & 165 & 81 & 18 \\
\hline No & 2 & 205 & 416 & 18 & 517 & 111 & 13 \\
\hline$P$-value & 0.0001 & & & & 0.0001 & & \\
\hline
\end{tabular}

**: chi-squared for linear trend.

The occurrence of large numbers of naevi among their parents was reported by 253 of the subjects and among their siblings by 141. In 130 families, large numbers of naevi occurred in both parents and siblings. A statistically significant association was detected between a positive family history of a large number of melanocytic naevi and the prevalence of CMN or CAMN (Table 7).

\section{Attitude of the schoolchildren to melanoma prevention}

The vast majority of the participants $(99.3 \%)$ had heard of the harmful effects of solar radiation and of the potential role of a large number of melanocytic naevi on the skin as a risk factor for the development of MM (88.65\%). Only $47.53 \%$ of them checked their pigmented skin lesions regularly either by self-examination or through consultation with a dermatologist.

\section{Discussion}

MM is a public health problem worldwide, and it is therefore essential to take measures towards primary and secondary prevention. Identification of the constitutional and environmental factors which contribute to the development of the disease, and hence identification of the individuals at high risk of cutaneous MM, is an indispensable step in all primary prevention efforts.

The number of CMN and the presence of CAMN are well-established indicators of a highly increased risk of cutaneous MM development. As adolescence and young adulthood are critical periods for the development of both CMN and CAMN, we set out to determine the prevalence of these pigmented lesions among 14- to 18-year-old schoolchildren. There are only a few reports on the rate of occurrence of CAMN in this age group. Rivers et al. surveyed 6- to 15-year-old Australian schoolchildren; 3.9\% of them already had CAMN by the age of 6 years, and the prevalence had increased to $21 \%$ by the age of 15 years. ${ }^{41}$ A similar study in Lithuania revealed that $7 \%$ of the examined children had CAMN. The prevalence of CAMN increased with age: it was $16 \%$ among those aged 14 and 15 years. ${ }^{42}$ Carli et al. reported a $20.9 \%$ rate of CAMN among Italian schoolchildren aged 13 and 14 years. ${ }^{37}$ Ballone et al. demonstrated an extremely high CAMN prevalence rate of $37.2 \%$ among healthy males aged 18 
and 19 years. ${ }^{43}$ In a study by Green et al., $13 \%$ of the examined children (7-1 1 years) had at least one CAMN. ${ }^{39}$ Our study population displayed a markedly high prevalence of CAMN. Moreover, a considerable proportion of them had multiple CMN.

$\mathrm{CN}$ are pigmented lesions that are usually present at birth or first become clinically apparent during infancy. $\mathrm{CN}$ are classified into three categories by size: small naevi with a diameter $<1.5 \mathrm{~cm}$, medium naevi with a diameter between 1.5 and $19.9 \mathrm{~cm}$ and large naevi with a diameter $>20 \mathrm{~cm} .{ }^{44}$ There is convincing evidence that the presence of $\mathrm{CN}$, particularly large ones, is associated with an elevated risk of MM development. ${ }^{28}$ The frequency of $\mathrm{CN}$ in white newborns is approximately $1-2 \%$. Like others, ${ }^{41,42,45-48}$ we also observed a high prevalence of $\mathrm{CN} ; 6.21 \%$ of the participants had at least one lesion fulfilling the clinical criteria for $\mathrm{CN}$.

Our data on the strong positive correlation between the number of CMN and the prevalence of CAMN are similar to those published by other authors. ${ }^{36,42,43,48}$

In agreement with several other reports, ${ }^{26,31,34,37-39,45,46}$ we observed a substantially higher prevalence of CMN and CAMN in boys.

Our results showing that skin phototypes I and II are associated with a higher prevalence of CMN and CAMN are consistent with several previous results. ${ }^{30,31,35,37,39,41-43,45,46,48-50}$ Garbe et al..$^{26}$ and Karlsson et al. ${ }^{51}$ did not detect a difference in the number of CMN and in the prevalence of CAMN in relation to skin type, whereas other investigations indicated that individuals with more sun-sensitive skin had fewer naevi. ${ }^{38,52-55}$

There are conflicting results concerning the relationships between pigmentary characteristics and the prevalence of CMN and CAMN. Most of the previous studies emphasized a significant association between a fair complexion (light skin, eyes and hair) and the density of melanocytic naevi, which were most frequent in individuals with blue or green eyes, blond hair and fair skin. ${ }^{32-34,36,37,39,45,46}$ Some studies are inconsistent with these findings. Kelly et al. ${ }^{31}$ and Pope et al..$^{49}$ found increasing numbers of naevi with darkening hair colour. Several other surveys have reported no significant correlation between pigmentary traits and the prevalence of moles. ${ }^{30,35,38,42,48,51,52,56}$ In the present study, we did not observe a statistically significant difference in the number of CMN with regard to hair colour, but a lighter eye colour was associated with an increased risk of the development of CMN and CAMN. These inconsistencies may stem from the fact that these surveys were conducted in different populations and different age groups.

In our study, schoolchildren with a reported history of sunburn were more likely to have freckles and lentigines relative to those with no history of sunburn. We failed to reveal a positive relationship between the prevalence of CMN or CAMN and a sunburn history. Earlier, Karlsson et al. ${ }^{51}$ and Carli et al. ${ }^{33}$ reported similar results. The vast majority of the previous investigations detected statistically significant correlations between the number of episodes and the severity of sunburn and the density of CMN and CAMN, suggesting that intermittent acute intense sun exposure inducing sunburn is an important environmental factor for the development of melanocytic naevi. ${ }^{26,30,35-39,42,49}$

There are conflicting data on the effects of sunscreen use on melanocytic naevus counts in children. Several investigators have reported a significantly higher number of naevi among individuals who used sunscreens regularly. One possible explanation for these observations is that the frequent use of sunscreens encourages a longer sunbathing time, and thus the melanocytes of the skin are subjected to a greater amount of UV radiation. ${ }^{34,38,49,49,50,52,57-59} \mathrm{Nev}-$ ertheless, Gallagher et al. found that the use of broadspectrum sunscreens with SPF 30 attenuated the number of naevi in 309 schoolchildren from Vancouver. ${ }^{59}$ In accordance with the observation by Dennis et al., ${ }^{30}$ we did not observe any relationship between sunscreen use and the number of naevi.

Some authors have reported that children who spent much time outdoors during summer had more moles than those who mainly spent their spare time indoors, suggesting that chronic sun exposure is also relevant for the development of melanocytic naevi. ${ }^{39,49,51}$ Others, ${ }^{30,42}$ including ourselves, concluded that there was no significant association between the number of hours spent outdoors during sunny summer days and the prevalence of CMN.

In agreement with Karlsson et al., ${ }^{51}$ we could discern no relationship between the use of sun beds and the prevalence of CMN or CAMN.

Our study did not disclose a correlation between the frequency of naevi and a family history of MM, in accord with other reports. ${ }^{36,49,51}$ A family history of a large number of melanocytic naevi was associated with a significantly higher prevalence of CMN and CAMN. Green et al. observed that a history of MM in a child's firstor second-degree relatives was associated with an increased total number of naevi, and this was the only factor significantly associated with the number of large naevi $>5 \mathrm{~mm}$. Children whose mothers said that they themselves had many pigmented moles were more likely to have large numbers of melanocytic naevi than children whose mothers said that they had no moles. ${ }^{39}$

Our study describes the frequency of pigmented lesions in a Hungarian population aged 14 to 18 years. The survey was conducted in the south-east of Hungary, where the incidence of cutaneous MM is significantly higher than the Hungarian average. We observed a high prevalence of CAMN in the study population; and a substantial proportion 
of the subjects had multiple CMN, too. In view of the previous epidemiological studies which proved that the presence of a large number of melanocytic naevi is a strong predictor of future melanoma development, we assume that our results explain to a certain extent the relatively high incidence of $\mathrm{MM}$ in this region of the country. The Szeged area is the sunniest part of the country: the annual number of sunshine hours exceeds 2100 . Sunlight exposure is the most relevant exogenous risk factor for $\mathrm{MM}$, and it also exerts a considerable influence on the naevus count of an individual. This climatic characteristic can also affect both the naevus number and the incidence of melanoma in this region. Our findings are in good concordance with the survey by Green et al. ${ }^{39}$ who demonstrated an extremely high prevalence of benign melanocytic naevi among young children in Queensland, among the population with the highest known incidence of melanoma. Queensland is a region with approximately 3000 sunshine hours per year.

It is widely accepted that genetic factors are also involved in both naevus formation and melanoma development. Accordingly, further research is necessary in order to define the genetic predisposition of our population for melanocytic naevi and melanoma development.

The main message of our survey is that health educational programmes should be aimed at young age groups. Regular surveillance of individuals at an enhanced risk of the development of melanoma is a crucial part of primary prevention. Through health educational campaigns and adequate screening programmes, whereby high-risk persons can be identified and directed into regular care, a considerable reduction in melanoma mortality can hopefully be achieved.

\section{Acknowledgement}

This study was supported by the National Fund of the Hungarian Ministry of Health (ETT 500/2006 grant).

\section{References}

1 de Vries E, Coebergh JW. Cutaneous malignant melanoma in Europe. Eur J Cancer 2004; 40: 2355-2366.

2 Marks R. Epidemiology of melanoma. Clin Exp Dermatol 2000; 25: 459-463.

3 Garbe C, Buttner P, Weiss J et al. Risk factors for developing cutaneous melanoma and criteria for identifying persons at risk: multicenter case-control study of the Central Malignant Melanoma Registry of the German Dermatological Society. J Invest Dermatol 1994; 102: 695699.

4 MacKie RM. Incidence, risk factors and prevention of melanoma. Eur J Cancer 1998; 34(Suppl. 3): S3-S6 S3-S6.
5 Rigel DS, Carucci JA. Malignant melanoma: prevention, early detection, and treatment in the 21 st century. CA Cancer J Clin 2000; 50: 215-236.

6 Bastuji-Garin S, Diepgen TL. Cutaneous malignant melanoma, sun exposure, and sunscreen use: epidemiological evidence. Br J Dermatol 2002; 146 (Suppl. 61): 24-30.

7 Herd RM, Cooper EJ, Hunter JA et al. Cutaneous malignant melanoma. Publicity, screening clinics and survival - the Edinburgh experience 1982-90. Br J Dermatol 1995; 132: 563-570.

8 Gaudi I, Kásler M. A rosszindulatú daganatos halálozás változása 1975 és 2001 között Magyarországon. Magy Onkol 2002; 46: 291-295.

9 Gaudi I, Kásler M. Melanomás megbetegedések a Nemzeti Rákregiszter alapján. Magy Onkol 2003; 47: 13-17.

10 Ottó S, Kásler M. A hazai és nemzetközi daganatos halálozási és megbetegedési mutatók alakulása. A népegészségügyi programok jellegzetességei és várható eredményei. Magy Onkol 2005; 49: 99-107.

11 Ottó S, Kásler M. Rákmortalitás és -incidencia hazánkban, az európai adatok tükrében. Magy Onkol 2002; 46: 111-117.

12 Kopf AW, Kripke ML, Stern RS. Sun and malignant melanoma. J Am Acad Dermatol 1984; 11: 674-684.

13 Rodenas JM, Delgado-Rodriguez M, Herranz MT, Tercedor $\mathrm{J}$, Serrano S. Sun exposure, pigmentary traits, and risk of cutaneous malignant melanoma: a case-control study in a Mediterranean population. Cancer Causes Control 1996; 7: 275-283.

14 Cho E, Rosner BA, Feskanich D, Colditz GA. Risk factors and individual probabilities of melanoma for whites. J Clin Oncol 2005; 23: 2669-2675.

15 Naldi L, Altieri A, Imberti GL et al. Sun exposure, phenotypic characteristics, and cutaneous malignant melanoma. An analysis according to different clinico-pathological variants and anatomic locations (Italy). Cancer Causes Control 2005; 16: 893-899.

16 Garbe C, Kruger S, Stadler R, Guggenmoos-Holzmann I, Orfanos CE. Markers and relative risk in a German population for developing malignant melanoma. Int J Dermatol 1989; 28: 517-523.

17 MacKie RM, Aitchison T. Severe sunburn and subsequent risk of primary cutaneous malignant melanoma in scotland. Br J Cancer 1982; 46: 955-960.

18 Green A, Siskind V, Bain C, Alexander J. Sunburn and malignant melanoma. Br J Cancer 1985; 51: 393-397.

19 Dubin N, Moseson M, Pasternack BS. Epidemiology of malignant melanoma: pigmentary traits, ultraviolet radiation, and the identification of high-risk populations. Recent Results Cancer Res 1986; 102: 56-75.

20 Green A, Bain C, McLennan R, Siskind V. Risk factors for cutaneous melanoma in Queensland. Recent Results Cancer Res 1986; 102: 76-97. 
21 Evans RD, Kopf AW, Lew RA et al. Risk factors for the development of malignant melanoma - I: Review of case-control studies. J Dermatol Surg Oncol 1988; 14: $393-$ 408.

22 Carli P, Biggeri A, Giannotti B. Malignant melanoma in Italy: risks associated with common and clinically atypical melanocytic nevi. J Am Acad Dermatol 1995; 32: 734-739.

23 Fargnoli MC, Piccolo D, Altobelli E, Formicone F, Chimenti $\mathrm{S}$, Peris K. Constitutional and environmental risk factors for cutaneous melanoma in an Italian population. A case-control study. Melanoma Res 2004; 14: 151-157.

24 Kraemer KH, Greene MH, Tarone R, Elder DE, Clark WH Jr., Guerry D 4th. Dysplastic naevi and cutaneous melanoma risk. Lancet 1983; 2: 1076-1077.

25 Kruger S, Garbe C, Buttner P, Stadler R, GuggenmoosHolzmann I, Orfanos CE. Epidemiologic evidence for the role of melanocytic nevi as risk markers and direct precursors of cutaneous malignant melanoma. Results of a case control study in melanoma patients and nonmelanoma control subjects. J Am Acad Dermatol 1992; 26: 920-926.

26 Garbe C, Buttner P, Weiss J et al. Associated factors in the prevalence of more than 50 common melanocytic nevi, atypical melanocytic nevi, and actinic lentigines: multicenter case-control study of the Central Malignant Melanoma Registry of the German Dermatological Society. J Invest Dermatol 1994; 102: 700-705.

27 Halpern AC, Guerry D, Elder DE et al. Dysplastic nevi as risk markers of sporadic (nonfamilial) melanoma. A case-control study. Arch Dermatol 1991; 127: 995-999.

28 Kanzler MH, Mraz-Gernhard S. Primary cutaneous malignant melanoma and its precursor lesions: diagnostic and therapeutic overview. J Am Acad Dermatol 2001; 45: 260-276.

29 Garbe C, Eigentler TK. Diagnosis and treatment of cutaneous melanoma: state of the art 2006. Melanoma Res 2007; 17: 117-127.

30 Dennis LK, White E, Lee JA et al. Constitutional factors and sun exposure in relation to nevi: a population-based cross-sectional study. Am J Epidemiol 1996; 143: 248-256.

31 Kelly JW, Rivers JK, MacLennan R, Harrison S, Lewis AE, Tate BJ. Sunlight: a major factor associated with the development of melanocytic nevi in Australian schoolchildren. J Am Acad Dermatol 1994; 30: 40-48.

32 Fritschi L, McHenry P, Green A, Mackie R, Green L, Siskind V. Naevi in schoolchildren in Scotland and Australia. Br J Dermatol 1994; 130: 599-603.

33 Carli P, Biggeri A, Nardini P, De Giorgi V, Giannotti B. Sun exposure and large numbers of common and atypical melanocytic naevi: an analytical study in a southern European population. Br J Dermatol 1998; 138: 422-425.

34 Darlington S, Siskind V, Green L, Green A. Longitudinal study of melanocytic nevi in adolescents. $J$ Am Acad Dermatol 2002; 46: 715-722.

35 Gallagher RP, McLean DI, Yang CP et al. Suntan, sunburn, and pigmentation factors and the frequency of acquired melanocytic nevi in children. Similarities to melanoma: the Vancouver Mole Study. Arch Dermatol 1990; 126: 770776.

36 Carli P, Biggeri A, Nardini P, Salani B, Giannotti B. Epidemiology of atypical melanocytic naevi: an analytical study in a Mediterranean population. Eur J Cancer Prev 1997; 6: 506-511.

37 Carli P, Naldi L, Lovati S, La Vecchia C. The density of melanocytic nevi correlates with constitutional variables and history of sunburns: a prevalence study among Italian schoolchildren. Int J Cancer 2002; 101: 375-379.

38 Dulon $M$, Weichenthal $M$, Blettner $M$ et al. Sun exposure and number of nevi in 5- to 6-year-old European children. J Clin Epidemiol 2002; 55: 1075-1081.

39 Green A, Siskind V, Hansen ME, Hanson L, Leech P. Melanocytic nevi in schoolchildren in Queensland. J Am Acad Dermatol 1989; 20: 1054-1060.

40 English DR, MacLennan R, Rivers JK, Kelly J, Armstrong BK. Epidemiological studies of melanocytic nevi: protocol for identifying and recording nevi. Internal Report 90/002. International Agency for Research on Cancer, Lyon, France, 1990.

41 Rivers JK, MacLennan R, Kelly JW et al. The eastern Australian childhood nevus study: prevalence of atypical nevi, congenital nevus-like nevi, and other pigmented lesions. J Am Acad Dermatol 1995; 32: 957-963.

42 Valiukeviciene S, Miseviciene I, Gollnick H. The prevalence of common acquired melanocytic nevi and the relationship with skin type characteristics and sun exposure among children in Lithuania. Arch Dermatol 2005; 141: 579-586.

43 Ballone E, Passamonti M, Lappa G, Di Plasio G, Fazii P. Pigmentary traits, nevi and skin phototypes in a youth population of Central Italy. Eur J Epidemiol 1999; 15: 189-195.

44 Rao BK, Wang SQ, Murphy FP. Typical dermoscopic patterns of benign melanocytic nevi. Dermatol Clin 2001; 19: 269-284.

45 Kallas M, Rosdahl I, Fredriksson M, Synnerstad I. Frequency and distribution pattern of melanocytic naevi in Estonian children and the influence of atopic dermatitis. J Eur Acad Dermatol Venereol 2006; 20: 143-148.

46 Synnerstad I, Nilsson L, Fredrikson M, Rosdahl I. Frequency and distribution pattern of melanocytic naevi in Swedish 8-9-year-old children. Acta Derm Venereol 2004; 84: 271-276.

47 Sigg C, Pelloni F, Schnyder UW. Frequency of congenital nevi, nevi spili and cafe-au-lait spots and their relation to nevus count and skin complexion in 939 children. Dermatologica 1990; 180: 118-123.

48 Augustsson A, Stierner U, Suurkula M, Rosdahl I. Prevalence of common and dysplastic naevi in a Swedish population. Br J Dermatol 1991; 124: 152-156.

49 Pope DJ, Sorahan T, Marsden JR, Ball PM, Grimley RP, Peck IM. Benign pigmented nevi in children. Prevalence and associated factors: the West Midlands, United Kingdom Mole Study. Arch Dermatol 1992; 128: 1201-1206. 
50 Luther H, Altmeyer P, Garbe C et al. Increase of melanocytic nevus counts in children during 5 years of follow-up and analysis of associated factors. Arch Dermatol 1996; 132: 1473-1478.

51 Karlsson P, Stenberg B, Rosdahl I. Prevalence of pigmented naevi in a Swedish population living close to the Arctic Circle. Acta Derm Venereol 2000; 80: 335-339.

52 English DR, Armstrong BK. Melanocytic nevi in children. I. Anatomic sites and demographic and host factors. Am J Epidemiol 1994; 139: 390-401.

53 Rampen FH, Fleuren BA, de Boo TM, Lemmens WA. Unreliability of self-reported burning tendency and tanning ability. Arch Dermatol 1988; 124: 885-888.

54 English JS, Swerdlow AJ, MacKie RM et al. Relation between phenotype and banal melanocytic naevi. Br Med J (Clin Res Ed) 1987; 294: 152-154.

55 Armstrong BK, de Klerk NH, Holman CD. Etiology of common acquired melanocytic nevi: constitutional variables, sun exposure, and diet. J Natl Cancer Inst 1986; 77: 329-335.
56 Breitbart M, Garbe C, Buttner P et al. Ultraviolet light exposure, pigmentary traits and the development of melanocytic naevi and cutaneous melanoma.

A case-control study of the German Central Malignant Melanoma Registry. Acta Derm Venereol 1997; 77: 374-378.

57 Bauer J, Buttner P, Wiecker TS et al. Interventional study in 1232 young German children to prevent the development of melanocytic nevi failed to change sun exposure and sun protective behavior. Int J Cancer 2005; 116: 755-761.

58 Autier P, Dore JF, Cattaruzza MS et al. Sunscreen use, wearing clothes, and number of nevi in 6- to 7-year-old European children. European Organization for Research and Treatment of Cancer Melanoma Cooperative Group. J Natl Cancer Inst 1998; 90: 1873-1880.

59 Gallagher RP, Rivers JK, Lee TK et al. Broad-spectrum sunscreen use and the development of new nevi in white children. JAMA 2000; 283: 2955-2960. 